\title{
A Prospective Observational Study on Polypharmacy in Geriatrics at A Private Corporate Hospital
}

\author{
Viswam K. Subeesh $^{1 *}$, Nair Gouri ${ }^{2}$, Elsa Thomas Beulah ${ }^{1}$, Velu Shivashankar ${ }^{1}$ \\ ${ }^{1}$ Department of Pharmacy Practice, Faculty of Pharmacy, MS Ramaiah University of Applied Sciences, Bangalore, India. \\ ${ }^{2}$ Department of Pharmacology; Faculty of Pharmacy, MS Ramaiah University of Applied Sciences, Bangalore, India. \\ ${ }^{3}$ Department of Pharmacy Practice; College of Pharmacy, Sri Ramakrishna Institute of Paramedical Science, Coimbatore, Tamilnadu, India.
}

\section{ARTICLE INFO \\ Article history: \\ Received on: 21/07/2017 \\ Accepted on: 05/10/2017 \\ Available online: $30 / 10 / 2017$}

Key words:

Polypharmacy, Geriatrics, Multiple Comorbidities,

Potentially inappropriate medications.

\begin{abstract}
Background: Geriatrics are the rapidly growing age group suffering with two or more chronic diseases leading to polypharmacy. Polypharmacy can boost the risk of adverse events, drug interactions and medication no adherence. This study aims at investigating the prevalence, different factors and consequences associated with polypharmacy in geriatrics.

Methodology: A prospective observational study was carried out for a duration of nine month in a private corporate hospital, Coimbatore, Tamil Nadu. Patients above 65 years were included in the study. The collected data was investigated for polypharmacy and analyzed for factors and consequences associated with polypharmacy.

Results: A total of 344 patients were included in the study. The average age of the study population was found to be $72.9 \pm 6.5$. Average hospital stay of the study population was found to be $10.22 \pm 8.7$ days. A total of 2034 drugs were prescribed for the study population. The average number of drugs prescribed for the study population was found to be $9.68( \pm 1.94)$ with minimum of 5 drugs to the maximum of 14 drugs during the study period, $110(52 \%)$ among the study population were found to be prescribed with potentially inappropriate medications. The mean value of drug related problems in the study population was found to be $1.81 \pm 1.3$.

Conclusion: The prevalence of polypharmacy and potentially inappropriate medications use were very high among the study population. This study assured the need of close monitoring of patients under polypharmacy since it can lead to higher number of drug related problems and increased hospital stay.
\end{abstract}

\section{INTRODUCTION}

People aged above 65years (Geriatrics) are the rapidly growing age group. Most of the geriatric population have two or more chronic diseases (Islam et al., 2014; Vu et al., 2004). Multiple comorbidity often leads to the use of more medications which is referred to as polypharmacy. Polypharmacy can be defined as either the concomitant use of five or more drugs or the administration of more medications in treating of multiple chronic diseases that are indicated clinically (Jyrkka et al., 2011, Reason et al., 2012). Adverse drug events, drug-drug and drug

\section{* Corresponding Author}

Dept. of Pharmacy Practice Faculty of Pharmacy MS Ramaiah University of Applied Sciences, Bangalore-54, India.

Email: subeeshkviswam @ gmail.com, Phone: +919895843219. disease interactions are strongly connected with polypharmacy (Mitty et al., 2009). Polypharmacy can also boost the risk of nonadherence, which results in suboptimal medication effectiveness and poor clinical consequences (Maher, 2014). If the medication non-adherence is not identified by the provider, they either increase the initial dose or add a second agent which in turn increases the health care costs and risk of adverse drug events (ADE) (Johnell and Klarin, 2007). A longitudinal study reported that the polypharmacy (use of 5 or more medications) increased the odds of an ADR related hospital visit by $88 \%$ compared with the use of fewer medications (Bourgeois et al., 2010) and it was also observed that each additional medication increase the risk by $7 \%$ (Damian et al., 2013; Vu et al., 2006). Increased ADR and associated expenditure results in the escalation of overall cost. 
Thus, it is significant to recognize the prevalence and factors associated with polypharmacy. A reduction in polypharmacy in turn results in reduction of morbidity, mortality and health expenditure (Johnell and Klarin, 2007, Parameswaran Nair, 2016). Over the past 2-3 decades, global health care is facing prominent issues associated with age, comorbidities and polypharmacy. On literature survey related to polypharmacy and its consequences among elderly, it is observed that most of the researches addressed western population (Maher et al., 2014; Nobili et al., 2011; Trumic et al., 2012). Even though few researchers studied polypharmacy among geriatrics in Indian population, the consequences and contributing factors associated with polypharmacy were addressed only in few studies. (Rambhade et al., 2012; Salwe et al., 2016). There is a need to evaluate the prevalence, factors and consequences of polypharmacy among elderly patients as they are the main consumers of drugs. This study aimed to investigate the prevalence and different factors associated with polypharmacy in geriatrics.

\section{METHODOLOGY}

The work entitled "a prospective observational study on polypharmacy in geriatrics at a private corporate hospital" was carried out for a duration of nine months in a private corporate hospital, Coimbatore, Tamilnadu. The protocol (Ref No. SRH/DEAN/F.19/2013) was presented and approval was taken from Institutional Human Ethics Committee (IHEC) before commencement of the study. The consent forms and study protocol were abided to the IHEC guidelines. Patient's age of 65 yrs. and above were included in the study and who were unwilling to participate in the study and out patients were excluded.

\section{Data Collection Procedure}

Regular ward rounds were carried out in all the wards of general medicine department by the researcher. Each patient's medication profile was reviewed. Patients who met the inclusion criteria were briefed on the project and consent was obtained. The data from medical chart were recorded in customized data entry form. The collected data were analyzed for factors and consequences associated with polypharmacy. DRPs were calculated by the sum of ADR, drug interaction and drug allergy.

\section{Statistical analysis}

The qualitative and quantitative data was presented in proportionality and mean respectively. The categorized data (comorbidities, number of drugs and number of DRPs) was compared by Chi-square test (or) Fischer's exact test. P value less than $(<0.05)$ was considered as statistically significant.

\section{RESULT}

\section{Prevalence}

According to inclusion and exclusion criteria, 344 patients were included in the study. Out of which, $210(61 \%)$ of the study subjects were on polypharmacy, who were enrolled for further evaluation and considered as the study population.

\section{Gender}

The study population consists $130(61 \%)$ males and 82 (39\%) were females (Fig.1).

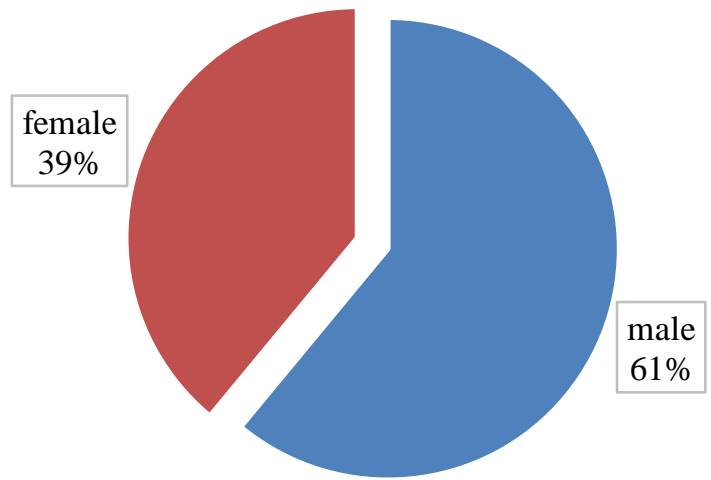

Fig. 1: Gender categorization.

Age

The result indicated that majority of the patients were in the age group of 65-69 years. The average age of the study population was found to be $72.9 \pm 6.5$ years with a maximum of 95 years.

\section{Social Status}

An attempt was made to understand the social habit of the study population (Fig. 2). The study revealed that $23(11 \%)$ patients were alcoholics, 31(15\%) patients were found to be smokers, $17(8 \%)$ patients were found to be smokers and alcoholics and $139(66 \%)$ patients were teetotalers in the overall population.

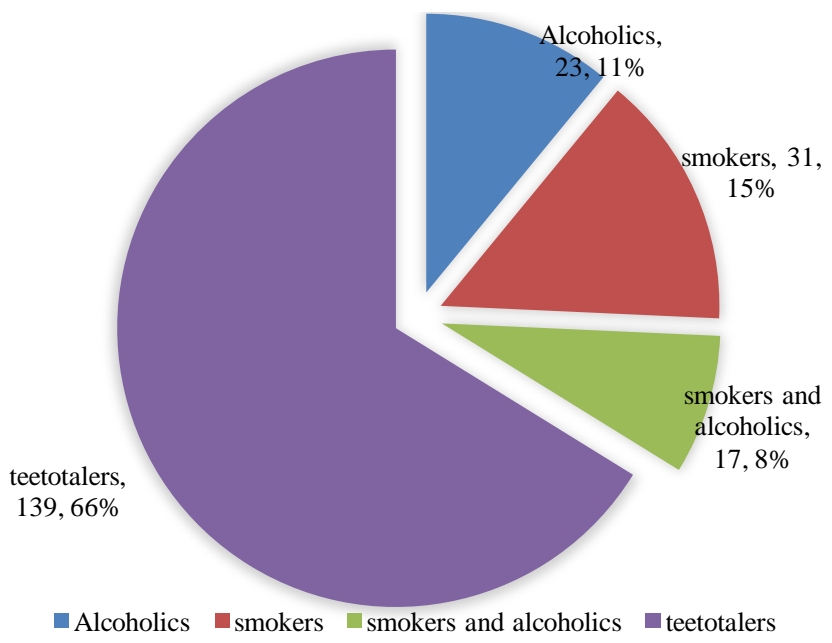

Fig. 2: Social Status.

\section{Comorbidity}

The comorbid conditions of the study population were analyzed (Fig. 3). 90 (43\%) of the study population had DM 
(Diabetes Mellitus), 61 (29\%) of the population had hypertension, 37 (18\%) were suffering from CVD (Cardio Vascular Diseases).

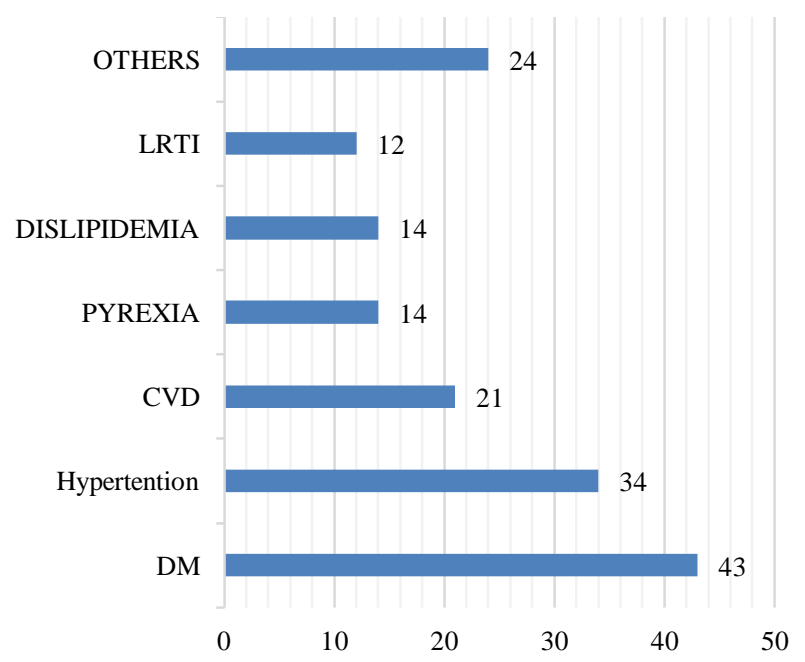

Fig. 3: Comorbidities.

\section{Number of comorbidities}

The number of disorders observed with the individual patient has revealed that $77 \%$ of the study population had a minimum of 2 comorbidities. The average number of comorbidity of the overall study population was found to be $2.54( \pm 1.86)$. The minimum number was 1 comorbidity and the maximum number was found to be 6 .

\section{Hospital stay}

The length of hospital stay of the study population was analyzed (Fig. 4) and the average hospital stay of the study population was found to be $10.22 \pm 8.7$ days. The maximum number of hospital stay was found to be 56 days and minimum number was 2 days.

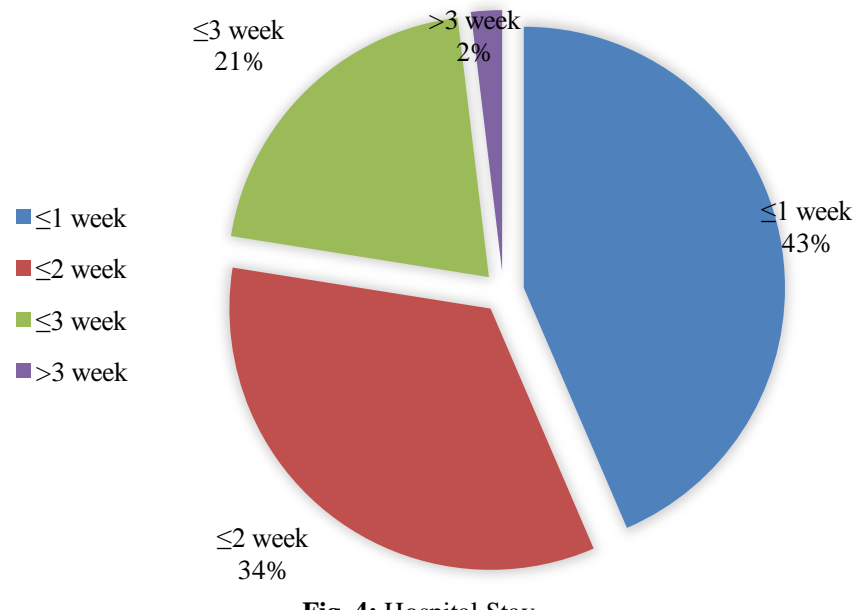

Fig. 4: Hospital Stay.

\section{Number of drugs}

The number of drugs prescribed for the study population was calculated (Fig.5). The result revealed that total of 2034 drugs was prescribed. The average number of drugs prescribed in the study population was found to be $9.68( \pm 1.94)$ with a minimum of 5 drugs to the maximum of 14 drugs. $60 \%$ of the study population was found to be under polypharmacy.

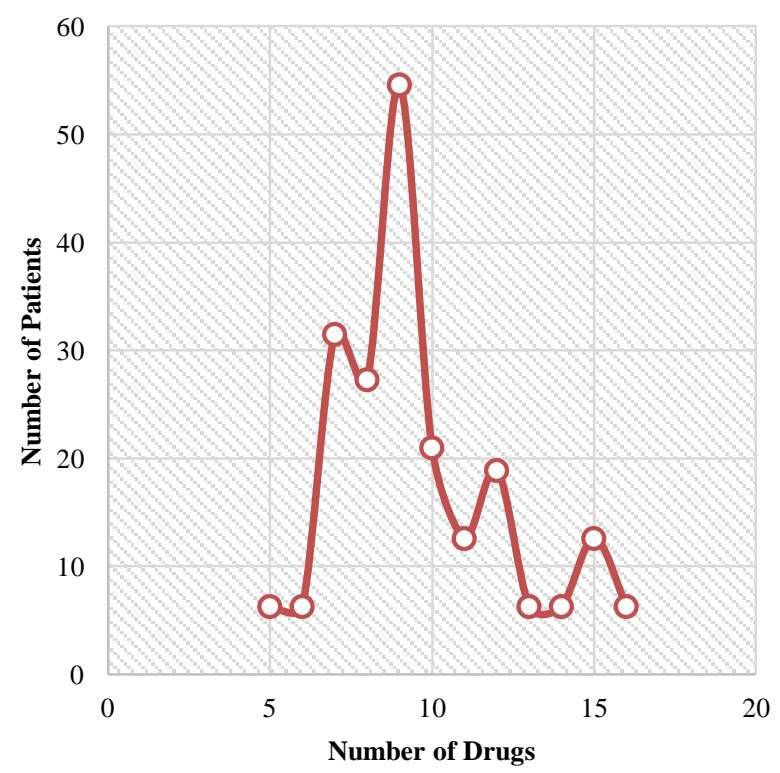

Fig. 5: Polypharmacy.

\section{Potentially Inappropriate Medications (PIMs)}

During the study period, $110(52 \%)$ of the study population were found to be prescribed with PIMs listed in Beers criteria.

\section{Adverse Drug Reaction}

A total number of 48 ADR were identified in the study population. In that, 34 were associated with PIM use and 14 ADR were associated with non-PIM use. The study result revealed that one among three PIM users were found to have at least one ADR.

\section{Drug Interaction}

The average number of drugs were $7.7( \pm 1.94)$. The average number of drug interactions per prescription was found to be $2.05( \pm 14.5)$.

\section{Drug Related Problems}

The DRP among the study population were analyzed (Fig.6) It was found that 27(13\%) of the study population were free from DRPs. Majority of the study population had at least one drug related problems. The mean value of DRP in the study population was found to be $1.81 \pm 1.3$ with maximum observed number of DRP per patient was six. 


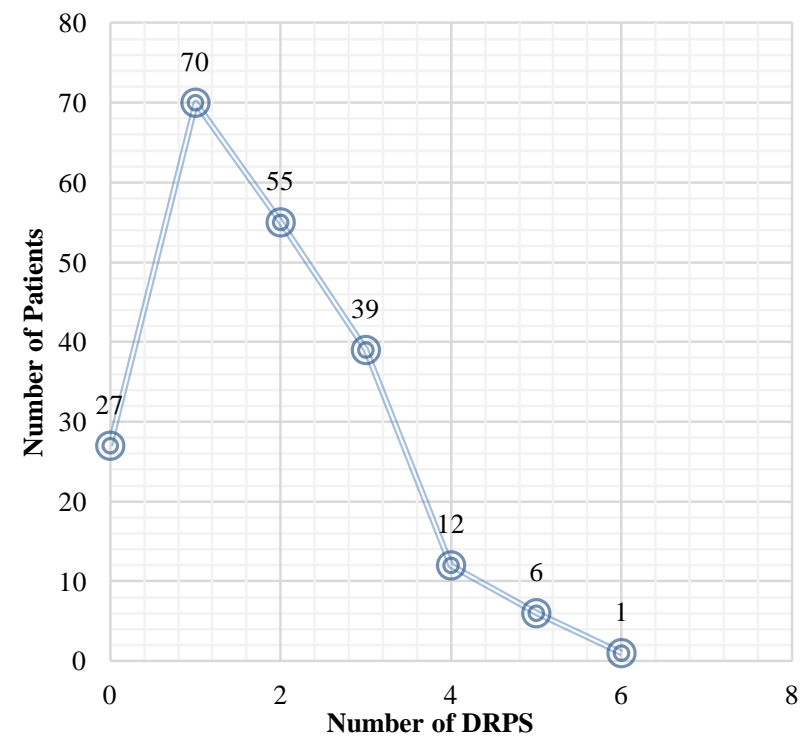

Fig. 6: Drug Related Problems in Study Population.

\section{Statistical Analysis}

On assessment of the association between "number of drugs" and "number of "Comorbidities" (Table.1), the result proved that "number of drugs" are statistically associated with "number of Comorbidities" at 0.01 level of significance. This result indicates that multiple comorbidities are one of the reasons for polypharmacy.

Table 1: Assessment of association between "number of drugs" and "number of Comorbidities" $(* \mathrm{P}<0.01)$.

\begin{tabular}{|c|c|c|c|c|c|c|}
\hline \multirow{2}{*}{ Variance } & & \multicolumn{3}{|c|}{ No. of Drugs } & \multirow{2}{*}{$\begin{array}{c}\text { Chi } \\
\text { square } \\
\text { value }\end{array}$} & \multirow{2}{*}{$P$ value } \\
\hline & & $5-8$ & $9-12$ & $12-16$ & & \\
\hline \multirow{5}{*}{$\begin{array}{c}\text { No. of } \\
\text { Comorbidities }\end{array}$} & 1 & 23 & 19 & 6 & \multirow{5}{*}{$21.82 *$} & \multirow{5}{*}{0.005} \\
\hline & 2 & 18 & 42 & 5 & & \\
\hline & 3 & 12 & 30 & 9 & & \\
\hline & 4 & 11 & 7 & 9 & & \\
\hline & 5 & 7 & 9 & 3 & & \\
\hline
\end{tabular}

\section{DISCUSSION}

The study highlights the prevalence of polypharmacy in the geriatric population which is in line with former researches (John and Kumar,2013, Nobili et al., 2011). It has been well established that there is an increased possibility of the intake of several medications including prescription, dietary or herbal supplements, non-prescription concurrently as geriatric population appears to be affected with multiple comorbidities. It has been found that age, comorbid conditions, number of drugs during hospital stay became the predictors of polypharmacy prevalence in in this study.

Polypharmacy was found to be predominant among males and the ratio of male to female was 3:2 which was similar to a study conducted by Nagaraju (2012) also reported that males are more susceptible to polypharmacy. The male predominance of polypharmacy among geriatrics is probably because they are more prone for multiple co-morbidities (Borah et al., 2017). The mean age of the study subjects was found to be $72.9 \pm 6.5$ years with a maximum of 95 years. The prevalence of polypharmacy was highest in the age group of 65-69 years. The multiple comorbidity results in reduced life expectancy which might be the reason for more number of patients in the age group of 65-69 years. Moreover average Indian life expectancy is in between 65-70 years (Cia,2015). The present study discloses majority of the patients were teetotalers which is contradictory to a similar study conducted by Dormann (2013) stating that smoking and alcohol use were common among their study population. This result might be biased because of the increased number of female population. Females are less likely to accept their alcoholism and smoking habits due to social stigma.

In the present study, the most common comorbid conditions were diabetes $(90 ; 43 \%)$, hypertension $(61 ; 29 \%)$ and $37(18 \%)$ were suffering from Cardio Vascular Disease (CVD). According to International Diabetic Foundation (IDF), India have maximum number of diabetes patients than any other country (Gale et al., 2010; Kaveeshwar and Cornwall, 2014). A statistical significant association was observed between comorbidities and polypharmacy. Majority of the study population had a minimum of 2 comorbidities which is similar to the report published by Papapetrou (2012), where the $31 \%$ of the study population had a minimum of 2 disorders. This shows that as the age progresses, the chances of multiple comorbidity is common (Wolff,2002) which in turn reflects the prevalence of polypharmacy among geriatrics (Lacro and Jeste, 1994, Park et al., 2012).

The average length of hospital stay was found to be 10.22 \pm 8.7 days which is alike to a study conducted by Nagaraju, Padmavathy (2012) that shows the majority of the population were discharged within a week. The average number of drugs prescribed in the study population was found to be $9.68( \pm 1.94)$ with minimum of 5 drugs to the maximum of 14 drugs. Majority of the study population was found to be under polypharmacy. A similar result observed in a study conducted by John and Kumar (2013) also reported polypharmacy prevalence to be very high among their study population. Geriatric population is more susceptible to polypharmacy (Damian et al., 2013, John and Kumar, 2013, Lacro and Jeste, 1994, Maher et al., 2014, Park et al., 2012). The current study indicates that several comorbid conditions needs to be taken into account as a predictor of polypharmacy and might require newer prescribed drugs over and beyond the past medication due to the worsening of the conditions. Moreover, physicians might add newer treatment regimen to treat the condition that resulted in hospital admission and also to prevent the potential adverse drug reactions like gastroprotective drugs for patients on antibiotics, NSAIDS etc. (Nobili et al.,2011).

PIM is a serious healthcare issue among geriatrics resulting in enhanced risk of drug related problems. The characteristics of PIM varies as geriatric population are cared in wide range of hospital settings, from intensive care to community (Miquel et al., 2010). During the study period, 110 (52\%) among the study population were found to be prescribed with PIMs listed in Beers criteria which was comparatively low to a similar study conducted by Praveen (2012) stating that PIM prevalence were 
$38 \%$ in their study population. The use of anxiolytics as a prophylaxis for hospital related anxiety might be the reason for high prevalence of PIM which is equivalent to the study conducted by Subeesh (Subeesh et al., 2015). The higher rate of PIM show that the health care professionals fails in monitoring the therapeutic regimen and adapts a disease-oriented approach (Nobili et al., 2011). Risk of ADRs among geriatrics is higher as they are on polypharmacy and necessitates to be vigilant on drug therapy safety (Subeesh et al., 2015). The present study revealed that one among three PIM users were found to have at least one ADR. Drug response in geriatrics might be unpredictable as the physiological functions are altered. PIMs were those drugs which risk over weigh the benefit. A study shows that DRPs are related to the drugs being used during hospital stay; addition of each drug increases the risk of DRPs which has occurred in over whole range of drugs (Viktil et al., 2007). It was found that 27(13\%) of the study population were free from DRPs while majority of the study population had at least one drug related problems. Conversely, polypharmacy might be appropriate and unavoidable in certain patients, when it is being cautiously prescribed and monitored.

\section{CONCLUSION}

The prevalence of polypharmacy is very high among geriatric population in the study site. The study supported the consequences of polypharmacy and was closely associated with multiple comorbidity and advanced age. A close and intensive monitoring of geriatrics in regard with polypharmacy could restrain the consequences. Clinical pharmacist could play crucial role in handling this crisis efficiently, by performing regular medication chart reviews, providing information and patient counselling regarding drug safety and polypharmacy. A multidisciplinary approach by involving physician, nurses and clinical pharmacist to work as a team is the best way of dealing with the challenges.

\section{Financial support and sponsorship: Nil.}

Conflict of Interests: There are no conflicts of interest.

\section{REFERENCE}

Borah L, Devi D, Debnath PK, Deka D. A study of drug utilization pattern of the geriatric patients in the department of geriatric medicine in a tertiary care hospital in assam, india. Asian J. Pharm. Clin. Res., 2017;10:122-126.

Bourgeois FT, Shannon MW, Valim C, Mandl KD. Adverse drug events in the outpatient setting: An 11-year national analysis. Pharmacoepidemiol. Drug Saf., 2010;19:901-10.

CIA. The world factbook life expectancy 2015 [Available from: https://www.cia.gov/library/publications/the-worldfactbook/rankorder/2102rank.html

Damian J, Pastor-Barriuso R, Valderrama-Gama E, de PedroCuesta J. Factors associated with falls among older adults living in institutions. BMC Geriatr., 2013;13:6.

Dormann H, Sonst A, Muller F, Vogler R, Patapovas A, Pfistermeister B, Plank-Kiegele B, Kirchner M, Hartmann N, Burkle T, Maas R. Adverse drug events in older patients admitted as an emergency:
The role of potentially inappropriate medication in elderly people (priscus). Dtsch. Arztebl. Int., 2013;110:213-9.

Gale j. India's diabetes epidemic cuts down millions who escape poverty: BloombergBussiness; 2010 [Available from: http://www.bloomberg.com/news/articles/2010-11-07/india-s-deadlydiabetes-scourge-cuts-down-millions-rising-to-middle-class.

Islam MM, Valderas JM, Yen L, Dawda P, Jowsey T, McRae IS. Multimorbidity and comorbidity of chronic diseases among the senior australians: Prevalence and patterns. PloS one, 2014;9:e83783.

John NN, Kumar NA. A study on polypharmacy in senior indian population. Int. J. Pharm. Biol. Sci., 2013;3:3.

Johnell K, Klarin I. The relationship between number of drugs and potential drug-drug interactions in the elderly: A study of over 600,000 elderly patients from the swedish prescribed drug register. Drug Saf., 2007;30:911-8.

Jyrkka J, Enlund H, Lavikainen P, Sulkava R, Hartikainen S. Association of polypharmacy with nutritional status, functional ability and cognitive capacity over a three-year period in an elderly population. Pharmacoepidemiol. Drug Saf., 2011;20:514-22.

Kaveeshwar SA, Cornwall J. The current state of diabetes mellitus in india. Australas Med. J., 2014;7:45-8.

Lacro JP, Jeste DV. Physical comorbidity and polypharmacy in older psychiatric patients. Biol. Psychiatry, 1994;36:146-52.

Maher RL, Hanlon J, Hajjar ER. Clinical consequences of polypharmacy in elderly. Expert Opin. Drug Saf., 2014;13:57-65.

Miquel MC, Cuervo MS, Silveira ED, Machuca IS, GonzálezBlazquez S, Errasquin BM, Cruz-Jentoft A. Potentially inappropriate drug prescription in older subjects across health care settings. Eur. Geriatr. Med., 2010;1:9-14.

Mitty E. Medication management in assisted living: A national survey of policies and practices. J. Am. Med. Dir. Assoc., 2009;10:107-14

Nagaraju B, Padmavathy G, Dattathreya G. Prevalence and assessment of polypharmacy in sri devraj urs medical college \& hospital, kolar. Int. J. Pharm. Sci., 2012;4:5.

Nobili A, Licata G, Salerno F, Pasina L, Tettamanti M, Franchi C, De Vittorio L, Marengoni A, Corrao S, Iorio A. Polypharmacy, length of hospital stay, and in-hospital mortality among elderly patients in internal medicine wards. The reposi study. Eur. J. Clin. Pharmacol., 2011;67:507-19.

Papapetrou, Jelastopulu I, Eleni, Symeonidou, Kleridou E, Floridou M, Demetra, Charalambous, Georgios. Investigation of polypharmacy and rational prescribing in elderly patients in a health centre of nicosia, cyprus. China-USA Business Review, 2012;11:1587.

Parameswaran Nair N, Chalmers L, Peterson GM, Bereznicki BJ, Castelino RL, Bereznicki LR. Hospitalization in older patients due to adverse drug reactions -the need for a prediction tool. Clin. Interv. Aging, 2016;11:497-505.

Park YW, Kim Y, Lee JH. Antipsychotic-induced sexual dysfunction and its management. World J. Mens Health, 2012;30:153-9.

Praveen K, Biradar K, Hafiz S, Karna K, Neelkanta P. Assessment of potentially inappropriate medication in elderly patients at basaveshwar teaching and general hospital. IJOPP, 2012;5:73-5.

Rambhade S, Chakarborty A, Shrivastava A, Patil UK, Rambhade A. A survey on polypharmacy and use of inappropriate medications. Toxicol. Int., 2012;19:68-73.

Reason B, Terner M, Moses McKeag A, Tipper B, Webster G. The impact of polypharmacy on the health of canadian seniors. Fam. Pract., 2012;29:427-32.

Salwe KJ, Kalyansundaram D, Bahurupi Y. A study on polypharmacy and potential drug-drug interactions among elderly patients admitted in department of medicine of a tertiary care hospital in puducherry. J. Clin. Diagn. Res., 2016;10:Fc06-10.

Subeesh KV, Shivashankar V, Gouri N, S Sriram, Seema S, Mamatha K. Assessment of sleep quality among hypnotic users in geriatric population - a prospective observational study. Am. J. PharmTech res., 2015;5:642-52.

Subeesh KV, Shivashankar V, Gouri N, Sriram S. A study on prevalence and impact of potentially inappropriate medication use in geriatrics at a private corporate hospital. Pharmanest, 2015;6:2845-8. 
Trumic E, Pranjic N, Begic L, Becic F. Prevalence of polypharmacy and drug interaction among hospitalized patients: Opportunities and responsabilities in pharmaceutical care. Mater Sociomed., 2012;24:68-72.

Viktil KK, Blix HS, Moger TA, Reikvam A. Polypharmacy as commonly defined is an indicator of limited value in the assessment of drug-related problems. Br. J. Clin. Pharmacol., 2007;63:187-95.

Vu MQ, Weintraub N, Rubenstein LZ. Falls in the nursing home: Are they preventable? J. Am. Med. Dir. Assoc., 2004;5:401-6.

$\mathrm{Vu}$ MQ, Weintraub N, Rubenstein LZ. Falls in the nursing home: Are they preventable? J. Am. Med. Dir. Assoc., 2006;7:S53-8.

Wolff JL, Starfield B, Anderson G. Prevalence, expenditures, and complications of multiple chronic conditions in the elderly. Arch. Intern. Med., 2002; 162: 2269-76.

\section{How to cite this article:}

Subeesh VK, Gouri N, Beulah TE, Shivashankar V. A Prospective Observational Study on Polypharmacy in Geriatrics at A Private Corporate Hospital. J App Pharm Sci, 2017; 7 (10): 162-167. 